\title{
A Schizophyllum commune fungus ball in a lung cancer cavity: a case report
}

\author{
Naoya Itoh ${ }^{1,2^{*}}$, Nana Akazawa ${ }^{1}$, Hiromi Murakami ${ }^{1}$, Yuichi Ishibana ${ }^{1}$, Yusuke Takahashi ${ }^{3}$, Waki Hosoda ${ }^{4}$, \\ Takashi Yaguchi ${ }^{5}$ and Katsuhiko Kamei ${ }^{5}$
}

\begin{abstract}
Background: Schizophyllum commune is a basidiomycete that lives in the environment and can cause infections, mainly those of the respiratory system. Although S. commune is increasingly reported as a cause of allergic bronchopulmonary mycosis and sinusitis, cases of fungal ball formation are extremely uncommon. Identification of S. commune is difficult using routine mycological diagnostic methods, and in clinically suspicious cases, internal transcribed spacer sequencing should be used for diagnosis. Here, we report a first case of lung cancer with a fungal ball formation of S. commune, confirmed by analyzing the internal transcribed spacer.

Case presentation: A 76-year-old man with diabetes and hypertension was admitted to the hospital with a chief complaint of hemosputum, which he had for about 19 months. A computed tomography image of the patient's chest showed a cavity and internal nodule in the left upper lobe of his lung. A left upper lobectomy was performed, and histopathological examination revealed squamous cell carcinoma of the lung and a fungal ball. The isolate from the surgical specimen was identified as S. commune by analyzing the internal transcribed spacer. The patient had no recurrence of the infection during 5 months of follow-up.
\end{abstract}

Conclusions: Only three cases of lung fungal balls caused by S. commune have been previously reported, and this is the first case of lung cancer cavity with a fungal ball formation. In cases of fungal ball formation in the lung, S. commune should be considered a possible causative microorganism.

Keywords: Schizophyllum commune, Fungal ball, Internal transcribed spacer sequencing, Lung cancer cavity

\section{Background}

Schizophyllum commune is an environmental basidiomycete that is widely distributed in nature and grows well on rotting wood and other plants [1]. It belongs to the phylum Basidiomycota, subphylum Agaricomycotina, and order Agaricales, which includes the fungi called mushrooms [2]. Identification of $S$. commune is problematic because it is most often cultured as sterile, cottony white colonies without spore formation [3, 4]. S. commune is characterized by clamp connections, hyphal spicules, and

\footnotetext{
*Correspondence: itohnaoya0925@ybb.ne.jp

${ }^{1}$ Division of Infectious Diseases, Aichi Cancer Center Hospital, 1-1

Kanokoden, Chikusa-ku, Nagoya, Aichi 464-8681, Japan

Full list of author information is available at the end of the article
}

formation of basidiocarps with basidiospores $[4,5]$. However, unlike dikaryotic isolates, monokaryotic isolates do not show characteristic spicules or clamp connections and cannot be identified using phenotypic methods; thus, genetic sequencing is required for identification [5]. The internal transcribed spacer (ITS) regions of fungal ribosomal DNA (rDNA) are highly variable sequences of preeminent concern in identifying fungal species through polymerase chain reaction (PCR) analysis [6].

Schizophyllum commune is rarely involved in human disease, but it is the most common basidiomycete among the filamentous fungi to cause infections in humans [1]. This fungus causes a wide range of clinical manifestations, from allergic reactions to invasive infections, but it is primarily responsible for infections of the respiratory 
system. Bronchopulmonary infections and sinusitis account for more than $90 \%$ of reported cases worldwide [7]. These localizations are consistent with natural airborne transmission through inhalation of basidiospores released into the atmosphere. The infection may remain localized or spread from the original site to other tissues and organs depending on factors such as the immune status of the host, deviation of the nasal septum, use of corticosteroid therapy, and duration of exposure to the spores [8].

Fungal balls of the lung are masses of fungal mycelium growing in existing cavities. They are found in patients with underlying lung diseases such as tuberculosis, a history of systemic fungal infections, recurrent bacterial pneumonia, lung abscesses, sarcoidosis, and cavitated squamous cell lung cancer $[4,9]$. In most cases, species of Aspergillus-most commonly A. fumigatus-or Scedosporium apiospermum (Pseudallescheria boydii) are involved [4]. Cases of pulmonary fungal ball formation caused by $S$. commune are extremely rare $[4,8,10]$. We report the first case of lung cancer cavity lesion with a fungal ball formation of S. commune. Sequencing analysis of the ITS was used to identify the microorganism.

\section{Case presentation}

A 76-year-old Japanese man with diabetes and hypertension was admitted to our hospital with hemosputum, a symptom which he had for about 19 months. The patient had gone to another hospital 19 months earlier for hemosputum and was diagnosed with a nodule $(42 \times 24 \mathrm{~mm})$ in the left upper lobe of his lung after undergoing a chest computed tomography scan. The chest scan from 18 months earlier showed that the nodule was associated with cavitation. A bronchoscopy was performed, but the cause of the hemosputum was not found. The patient was referred and then admitted to our hospital for diagnosis because the hemosputum persisted and lung cancer was suspected. The patient's medical interview conducted at our hospital revealed a history of a 3-month stay in Chiang Mai, Thailand, four years previously. There was no other history of dust or tuberculosis exposure, nor any family history, any pets, or any history of gardening or mountain hiking.

On examination, the patient appeared well. His temperature was $36.2{ }^{\circ} \mathrm{C}$, heart rate was $76 \mathrm{bpm}$ and regular, blood pressure was $147 / 81 \mathrm{mmHg}$, and oxygen saturation was $97 \%$ in room air. His physical examination findings were unremarkable. Laboratory investigations revealed a white blood cell count of $7090 / \mu \mathrm{L}$ (neutrophil count $4552 / \mu \mathrm{L}$, eosinophil count $177 / \mu \mathrm{L}$ ), hemoglobin level of $18.4 \mathrm{~g} / \mathrm{dL}, \mathrm{C}$-reactive protein level of $0.02 \mathrm{mg} / \mathrm{dL}$ (nor$\mathrm{mal}<0.30 \mathrm{mg} / \mathrm{dL}$ ), and hemoglobin A1c level of $7.5 \%$. His chest radiographs showed a cavitary lesion in the left middle lung field (Fig. 1). His chest scan showed a cavity $(42 \times 24 \mathrm{~mm})$ in the left upper lobe with an internal nodule $(13 \times 11 \mathrm{~mm})$ (Fig. 2). In addition to lung cancer, aspergilloma and tuberculosis were considered differential diagnoses. Serum beta-D-glucan and Aspergillus antibody tests were negative. Bacterial culture of his sputum showed oral commensals and methicillin-resistant Staphylococcus aureus. The culture and smear of three series of sputum for anti-acid bacteria were negative.

A thoracoscopic left upper lobectomy was performed on the patient, and he was discharged on the second postoperative day. Histopathological examination of the cavitary lesion in the left upper lobe revealed squamous cell carcinoma, and the nodule in the cyst was identified as a fungal ball with numerous filamentous fungi on Hematoxylin and eosin staining (Fig. 3). Lung specimens were cultured aerobically at $35{ }^{\circ} \mathrm{C}$ on a CHROMagar Candida plate (Kanto Chemical Co, Inc., Tokyo, Japan), sheep blood agar (Nissui Pharmaceutical Co., Ltd., Tokyo, Japan), and chocolate agar EX II (Nissui Pharmaceutical Co., Ltd., Tokyo, Japan). No growth was observed at $48 \mathrm{~h}$, and the incubation was continued at $25^{\circ} \mathrm{C}$. At $72 \mathrm{~h}$, small white colonies developed (Fig. 4). Lactophenol cotton blue mounts of slide cultures on CHROMagar of the isolated fungus showed hyaline hyphae with clamp connections and spicules, but no conidia (Fig. 5).

Since we were not able to identify the fungal species at our institution, we asked the Medical Mycology Research Center (MMRC), Chiba University to identify the fungi. The ITS sequencing of the isolated fungus was performed in MMRC. Based on the Basic Local Alignment Search Tool (BLAST) search of the sequence on the ITS region

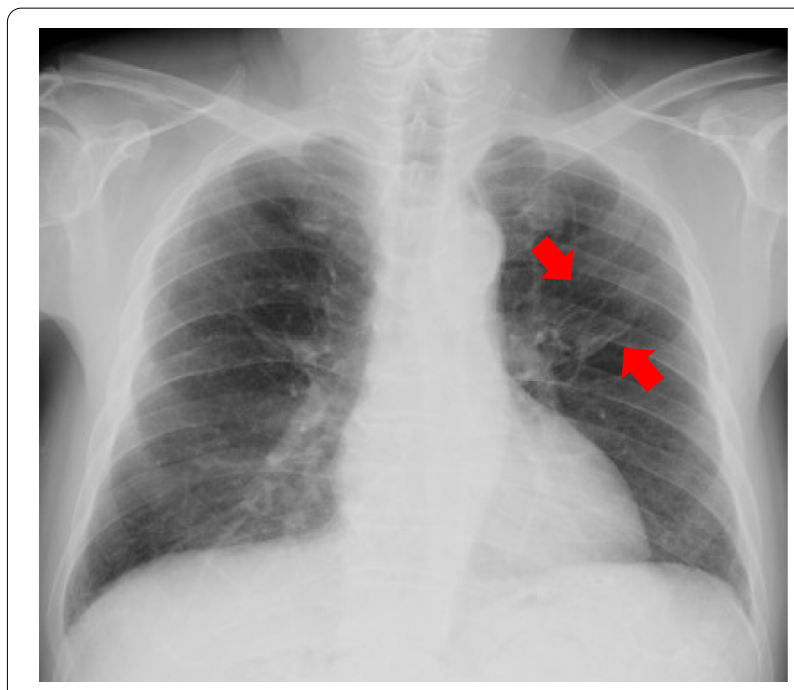

Fig. 1 Chest radiographs showing the cavitary lesion (red arrows) in the left middle lung field 

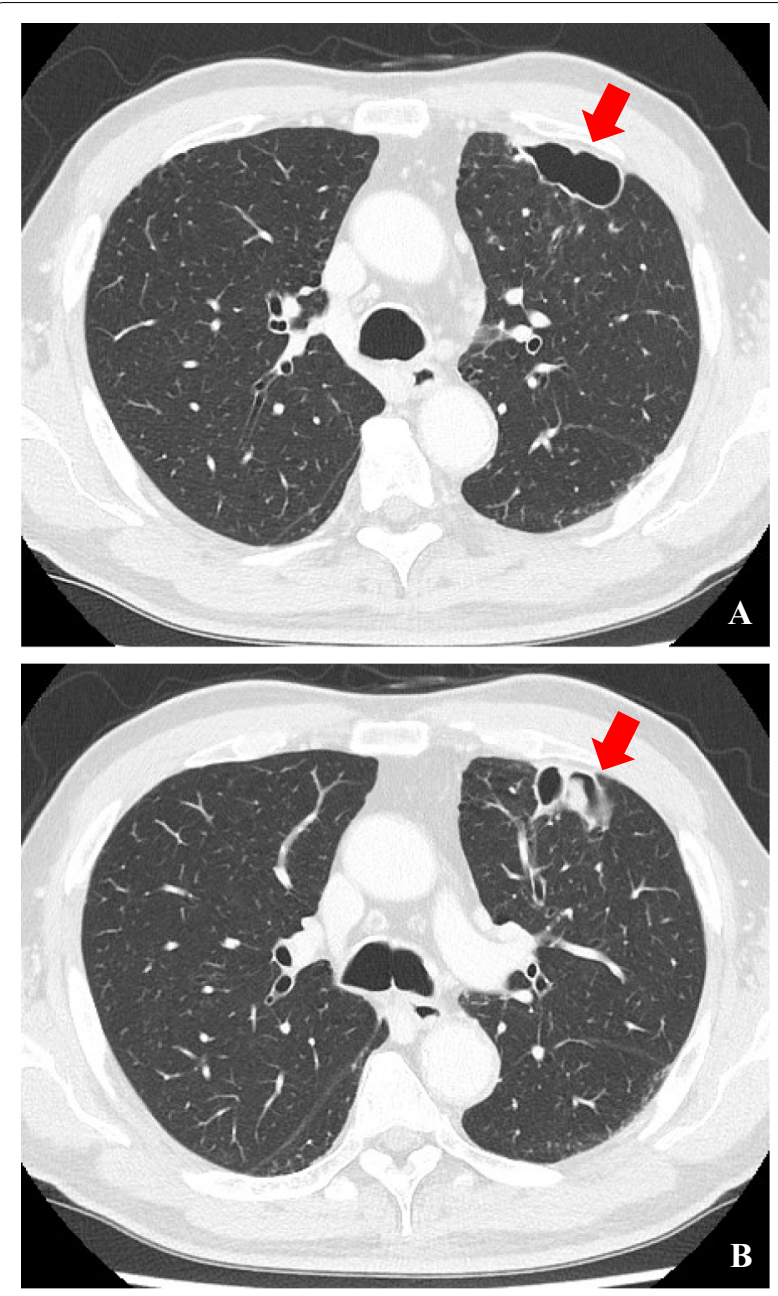

Fig. 2 Computed tomography scan of the thorax. The left upper lobe of the lung has a cavity $(\mathbf{A}, \mathbf{B})$ and internal nodule (B); these are indicated using red arrows

of the rRNA gene of the isolated fungus, the homology of the standard strain S. commune CBS 124811 (GenBank Accession No.: MH863418) was 99.8\% (617/618 bp) [11]. Thus, we identified the isolate as $S$. commune on phylogeny and deposited it as IFM 67,107 at MMRC, Chiba University, through the National Bio-resource Project, Japan. The final diagnosis was a fungal ball caused by $S$. commune in the cavity of the lung cancer. The patient has not experienced recurrence of symptoms in 5 months of follow-up.

\section{Discussion and conclusions}

We report the first case of lung cancer cavity with a fungal ball formation of $S$. commune identified by analyzing the ITS.

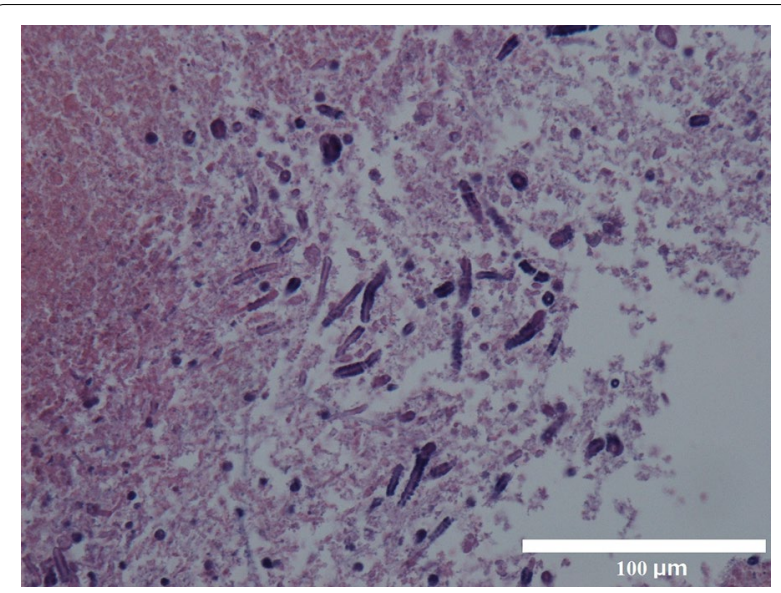

Fig. 3 Histologic section of a specimen obtained from the fungus ball showing septate fungal hyphae (hematoxylin and eosin staining) (magnification $\times 400,300 \mathrm{dpi}$ ). (This image was acquired and captured using a Nikon eclipse 55i microscope (Nikon, Japan) and a Nikon Digital Color Camera Sight DS-Fi-1 (Nikon, Japan)

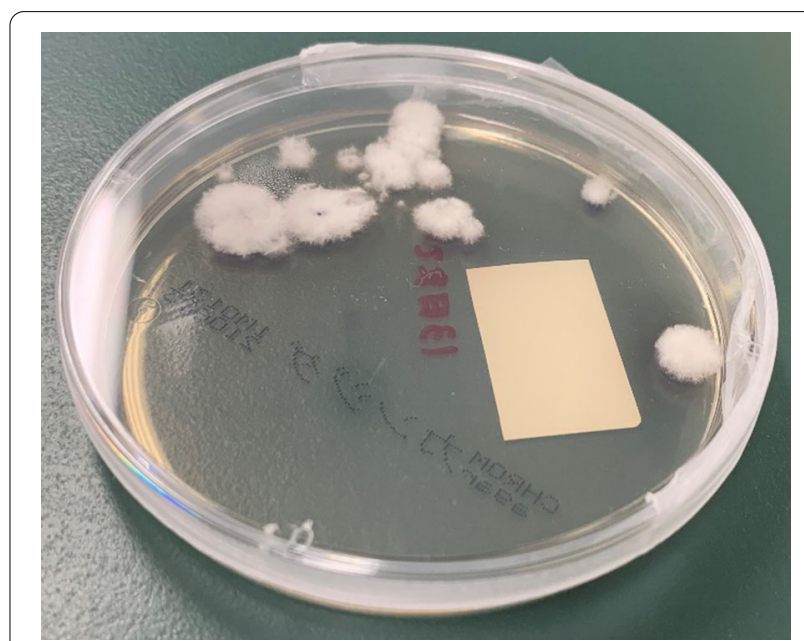

Fig. 4 Multiple white, woolly colonies of Schizophyllum commune after a 7-day incubation on a CHROMagar Candida plate

S. commune is a basidiomycete characterized by the formation of clamp connections, hyphal spicules, and basidiocarps with basidiospores [8]. The fungus is an opportunistic pathogen that can cause a wide range of clinical manifestations, including sinusitis, allergic bronchopulmonary mycosis, eye, ear, and skin infections, abscesses, and fungemia; however, human infections are rarely reported [1]. According to a previous worldwide study of the 71 cases of S. commune reported, $45(63 \%)$ were bronchopulmonary and $22(31 \%)$ were sinusitis [8]. There have been only three previous reports of fungal ball formation by $S$. commune $[4,8,10]$, and ours is 


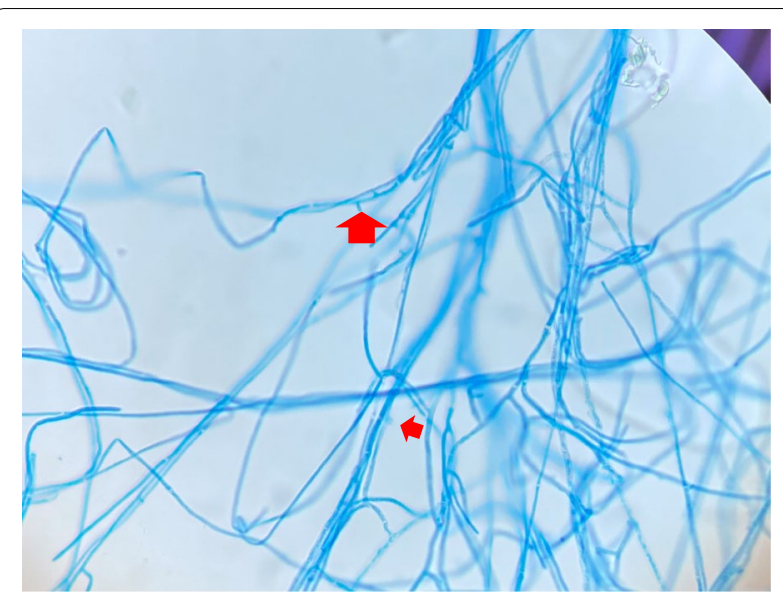

Fig. 5 Lactophenol cotton blue mount of slide culture on CHROMagar of Schizophyllum commune. The image shows the hyaline hyphae with clamp connections (small arrow) and spicules (large arrow). No conidia are visible. Photomicrograph obtained at $\times 400$ magnification (300 dpi)

the first case reported of it forming in a lung cancer cavity. S. commune is distributed all over the world [8], and the patient's history in Chiang Mai was not considered a special risk. However, it has been noted that infections caused by $S$. commune are underestimated [8]. S. commune is cultured according to a routine laboratory culture method as described in our case. Identification based solely on macro-microscopic characteristics of cultured colonies is challenging in practice because $S$. commune generally does not form spores and grows woolly, whitish, and sterile colonies [1]. Long incubation times are required for its characteristic macroscopic structures to develop, making cultured colonies impractical for clinical diagnosis [1]. Since the reference spectral library of matrix-assisted laser desorption ionization-time of flight mass spectrometry (MALDI-TOF MS) is still incomplete, timely use of molecular techniques should be considered the gold standard for diagnosing S. commune in clinically suspicious cases [12]. The infecting organism in our case was finally identified by analyzing the ITS, and a case of fungal ball formation within the lung cancer cavity caused by $S$. commune was diagnosed.

Most cases of fungal balls are associated with Aspergillus [4]. Certain imaging features-such as the air crescent sign, meniscus sign, and ball-in-hole sign-are associated with the presence of a fungal ball, which results in a collection of air that is shaped like a crescent and that separates the wall of the cavity from an internal mass [13-15]. These imaging findings have been reported to be associated with a variety of other diseases, and differential diagnosis can be difficult. Other causes of intracavitary masses surrounded by a crescent of air include other fungi, pulmonary hydatid cyst, Rasmussen aneurysm, pulmonary gangrene, intracavitary clot, textiloma, lung cancer, metastases, and teratoma [16]. In our case, the possibility of lung cancer, aspergilloma, or tuberculosis was considered preoperatively, but the nodule was finally diagnosed as a fungal ball of S. commune that had developed in the cavity of the lung cancer. There are very few reports of fungal ball formation within the lung cancer cavity, and all are due to aspergilloma $[9,17,18]$. The possibility of cell-cell interactions (i.e., between the cancer and Aspergillus) and their impact on the growth, differentiation, and overall invasiveness of these cancers has not been studied [19]. In our case, the relationship between lung cancer and S. commune is unclear, but it was shown that $S$. commune can form a fungus ball in lung cancer cavities. Therefore, S. commune infection should be considered one of the causes in cases with pulmonary fungal balls.

Symptoms of and risk factors for fungal balls caused by $S$. commune are still unknown due to the scarcity of reports. However, according to previous reports $[4,8,10]$ and ours, three out of four patients had blood sputum and hemoptysis, and three out of four had diabetes mellitus (Table 1). Only one of the four patients had no history or symptoms of diabetes. Since our patient had diabetes mellitus, as did patients in previous reports, diabetes was considered a risk factor.

The role of surgery and antifungal therapy in cases of a fungal ball caused by $S$. commune remains unclear due to the rarity of reports on these clinical manifestations and limited experience in their management. Of the four cases reported to date, including our own, three were treated with lobectomy alone without antifungal therapy; one patient was treated with itraconazole for 4 months. Data on in vitro antifungal susceptibility testing of $S$. commune are scarce. Previous reports have shown that antifungal susceptibility testing of itraconazole, voriconazole, and amphotericin B resulted in very low minimum inhibitory concentrations [5, 20-24]. In this case, although drug susceptibility testing was not performed, considering that the condition was similar to simple pulmonary aspergilloma, surgical treatment was appropriate. In addition, no recurrence was observed at the 5-month postoperative follow-up. The disease recurrence after lobectomy remains unknown, and whether the same treatment plan as that for aspergilloma is appropriate requires further studies. However, our patient is being carefully followed up in an outpatient clinic, and no recurrence has been observed at 5 months after surgery.

In conclusion, we report the first case of lung cancer cavity lesion with a fungal ball formation of $S$. commune. The case was diagnosed by analyzing the ITS, and the patient underwent lobectomy, with no sign of 
Table 1 Summary of published cases of fungal balls due to Schizophyllum commune

\begin{tabular}{|c|c|c|c|c|c|c|c|}
\hline $\begin{array}{l}\text { Author, country, } \\
\text { year, reference }\end{array}$ & Age (years), sex & Symptoms & $\begin{array}{l}\text { Underlying } \\
\text { condition }\end{array}$ & Diagnostic method & $\begin{array}{l}\text { Susceptibility MEC } \\
\text { or MIC }(\mu \mathrm{g} / \mathrm{mL})\end{array}$ & Treatment & Outcome \\
\hline $\begin{array}{l}\text { Sigler, Canada, 1995, } \\
\text { [4] }\end{array}$ & $53, F$ & $\begin{array}{l}\text { Cough } \\
\text { Hemoptysis }\end{array}$ & $\mathrm{TB}, \mathrm{DM}$ & $\begin{array}{l}\text { Morphotype, Analyz- } \\
\text { ing ITS }\end{array}$ & ND & Lobectomy & Survived \\
\hline $\begin{array}{l}\text { Chowdhary, India, } \\
\text { 2013, [8] }\end{array}$ & $42, M$ & Hemoptysis & $\mathrm{TB}, \mathrm{DM}$ & $\begin{array}{l}\text { Morphotype, Immu- } \\
\text { nodiffusion test, } \\
\text { Specific IgE, Skin } \\
\text { test, Analyzing ITS }\end{array}$ & $\begin{array}{l}\text { ITC }<0.06-0.125 ; \\
\text { VRC } 0.5-1 ; \text { POS } \\
0.015-0.125 ; \text { AMB } \\
0.5-1 ; \text { CAS } 0.125-0.5 ; \\
\text { AFG } 0.125-0.5 ; \text { MFG } \\
0.125-0.5\end{array}$ & $\begin{array}{l}\text { Systemic } \\
\text { glucocorti- } \\
\text { coids } \\
\text { ITC, } \\
4 \text { months }\end{array}$ & Survived \\
\hline $\begin{array}{l}\text { Sakaguchi, Japan, } \\
2018,[10]\end{array}$ & $58, F$ & None & None & $\begin{array}{l}\text { Morphotype, Analyz- } \\
\text { ing ITS }\end{array}$ & ND & Lobectomy & Survived \\
\hline Present case & $76, M$ & Hemosputum & Lung cancer, DM, HT & $\begin{array}{l}\text { Morphotype, Analyz- } \\
\text { ing ITS }\end{array}$ & ND & Lobectomy & Survived \\
\hline
\end{tabular}

MEC, Minimum effective concentrations; MIC, minimum inhibitory concentration; F, female; M, male; ND, not done; DM, diabetes mellitus; TB, tuberculosis; HT, hypertension; $\mathrm{AMB}$, amphotericin $\mathrm{B}$; IgE, immunoglobin $\mathrm{E}$; ITC, itraconazole; FLC, fluconazole; VRC, voriconazole; MFG, micafungin; POS, posaconazole; CAS,

recurrent infection 5 months after the surgery. In cases of fungal ball formation in the lung, S. commune should be considered a possible causative microorganism.

\section{Abbreviations \\ BLAST: Basic Local Alignment Search Tool; MALDI-TOF MS: Matrix-assisted laser desorption ionization-time of flight mass spectrometry; ITS: Internal tran- scribed spacer; MMRC: Medical Mycology Research Center; PCR: Polymerase chain reaction; rDNA: Recombinant DNA.}

\section{Acknowledgements}

We acknowledge the excellent assistance of the bacterial laboratory staff of Aichi Cancer Center Hospital, Medical Mycology Research Center, Chiba University, and the National Bio-resource Project in Japan.

\begin{abstract}
Authors' contributions
All authors meet the ICMJE authorship criteria. NI was involved in literature review, planning the study, and writing of the manuscript. HM, YI, WH, TY, and $\mathrm{KK}$ conducted the laboratory analyses. $\mathrm{NI}, \mathrm{NA}$, and $\mathrm{YT}$ were involved in the patient's care. All the authors interpreted the data, drafted and critically revised the manuscript. All authors read and approved the final manuscript.
\end{abstract}

\section{Funding}

This research did not receive any specific grants from funding agencies in the public, commercial, or not-for-profit sectors.

\section{Availability of data and materials}

The data used and/or analyzed during the current study are available from the corresponding author on reasonable request.

\section{Declarations}

\section{Ethics approval and consent to participate}

Not applicable.

\section{Consent for publication}

Written informed consent was obtained from the patient for publication of this case report and any accompanying images. A copy of the written consent is available for review by the Editor of this journal.

\section{Competing interests}

The authors declare that they have no competing interests.

\section{Author details}

'Division of Infectious Diseases, Aichi Cancer Center Hospital, 1-1 Kanokoden, Chikusa-ku, Nagoya, Aichi 464-8681, Japan. ${ }^{2}$ Collaborative Chairs Emerging and Reemerging Infectious Diseases, National Center for Global Health and Medicine, Graduate School of Medicine, Tohoku University, 2-1 Seiryo-machi, Aoba-ku, Sendai, Miyagi 980-8575, Japan. ${ }^{3}$ Department of Thoracic Surgery, Aichi Cancer Center Hospital, 1-1 Kanokoden, Chikusa-ku, Nagoya, Aichi 464-8681, Japan. ${ }^{4}$ Department of Pathology and Molecular Diagnostics, Aichi Cancer Center Hospital, 1-1 Kanokoden, Chikusa-ku, Nagoya, Aichi 464-8681, Japan. ${ }^{5}$ Medical Mycology Research Center, Chiba University, 1-8-1 Inohana, Chiba 260-8673, Japan.

Received: 2 August 2021 Accepted: 27 September 2021

Published online: 09 October 2021

\section{References}

1. Cavanna C, Pagella F, Esposto MC, Tamarozzi F, Clemente L, Marone P, et al. Human infections due to Schizophyllum commune: case report and review of the literature. J Mycol Med. 2019;29:365-71.

2. Hibbett DS, Binder M, Bischoff JF, Blackwell M, Cannon PF, Eriksson OE, et al. A higher-level phylogenetic classification of the fungi. Mycol Res. 2007;111:509-47.

3. Pounder Jl, Simmon KE, Barton CA, Hohmann SL, Brandt ME, Petti CA. Discovering potential pathogens among fungi identified as nonsporulating molds. J Clin Microbiol. 2007:45:568-71.

4. Sigler L, de la Maza LM, Tan G, Egger KN, Sherburne RK. Diagnostic difficulties caused by a nonclamped Schizophyllum commune isolate in a case of fungus ball of the lung. J Clin Microbiol. 1995;33:1979-83.

5. Chowdhary A, Kathuria S, Singh PK, Agarwal K, Gaur SN, Roy P, et al. Molecular characterization and in vitro antifungal susceptibility profile of Schizophyllum commune, an emerging basidiomycete in bronchopulmonary mycoses. Antimicrob Agents Chemother. 2013;57:2845-8.

6. Martin KJ, Rygiewicz PT. Fungal-specific PCR primers developed for analysis of the ITS region of environmental DNA extracts. BMC Microbiol. 2005;18(5):28.

7. Chan JFW, Teng JLL, Li IWWS, Wong SCY, Leung SSM, Ho PO, et al. Fatal empyema thoracis caused by Schizophyllum commune with cross-reactive cryptococcal antigenemia. J Clin Microbiol. 2014;52:683-7.

8. Chowdhary A, Randhawa HS, Gaur SN, Agarwal K, Kathuria S, Roy P, et al. Schizophyllum commune as an emerging fungal pathogen: a review and report of two cases. Mycoses. 2013;56:1-10. 
9. Smahi M, Serraj M, Ouadnouni Y, Chbani L, Znati K, Amarti A. Aspergilloma in combination with adenocarcinoma of the lung. World J Surg Oncol. 2011;27:9-27.

10. Sakaguchi Y, Chiba N, Saito M, Ishikawa S, Nakagawa T. Resection of a lung nodule infected with Schizophyllum commune initially suspected of being lung cancer. J Japanese Assoc Chest Surg. 2018;32:464-8.

11. Vu D, Groenewald M, de Vries M, Gehrmann T, Stielow B, Eberhardt U, et al. Large-scale generation and analysis of filamentous fungal DNA barcodes boosts coverage for kingdom fungi and reveals thresholds for fungal species and higher taxon delimitation. Stud Mycol. 2019;92:135-54.

12. Chowdhary A, Singh PK, Kathuria S. Reply to "Matrix-assisted laser desorption ionization-time of flight identification of Schizophyllum commune: perspectives on the review by Chowdhary et al." Med Mycol. 2015;53:898-9.

13. Knower MT, Kavanagh P, Chin R Jr. Intracavitary hematoma simulating mycetoma formation. J Thorac Imaging. 2002;17:84-8.

14. Yasuda M, Nagashima A, Haro A, Saitoh G. Aspergilloma mimicking a lung cancer. Int J Surg Case Rep. 2013;4:690-2.

15. Marchiori E, Zanetti G, Barreto MM. Teratoma: another cause of the air crescent sign. QJM. 2015:108:431.

16. Sevilha JB, Rodrigues RS, Barreto MM, Zanetti G, Hochhegger B, Marchiori E. Infectious and non-infectious diseases causing the air crescent sign: a state-of-the-art review. Lung. 2018;196:1-10.

17. Saleh W, Ostry A, Henteleff H. Aspergilloma in combination with adenocarcinoma of the lung. Can J Surg. 2008;51:E3-4.

18. Nakajima K, Yamada G, Tanaka H, Saizen H, Nagata M, Tanaka S, et al. A case of combined squamous cell carcinoma and aspergilloma arising in a cyst wall. Nihon Kokyuki Gakkai Zasshi. 2001;39(12):961-5.
19. Boyd M, Ojha S, Goyos J, Cragun WH, Rubio E. Invasive pulmonary aspergillosis and lung adenocarcinoma: case report. Thorac Cancer. 2013:4:212-4

20. Maeda M, Maeda T, Nakamura A, Komatsu M. A case of otitis externa caused by Schizophyllum commune: an approach to antimicrobial stewardship using Gram staining of otorrhea in a medical clinic. J Infect Chemother. 2019;25:731-4.

21. González GM, Sutton DA, Thompson E, Tijerina R, Rinaldi MG. In vitro activities of approved and investigational antifungal agents against 44 clinical isolates of basidiomycetous fungi. Antimicrob Agents Chemother. 2001:45:633-5.

22. Kondori N, Svensson E, Mattsby-Baltzer I. In vitro susceptibility of filamentous fungi to itraconazole, voriconazole and posaconazole by Clinical and Laboratory Standards Institute reference method and E-test. Mycoses. 2011;54:e318-22.

23. Miyazaki Y, Sakashita H, Tanaka T, Kamei K, Nishimura K, Yoshizawa Y. Mucoid impaction caused by monokaryotic mycelium of Schizophyllum commune in association with bronchiectasis. Intern Med. 2000;39:160-2.

24. Tullio V, Mandras N, Banche G, Allizond V, Gaido E, Roana J, et al. Schizophyllum commune: an unusual of agent bronchopneumonia in an immunocompromised patient. Med Mycol. 2008;46:735-8.

\section{Publisher's Note}

Springer Nature remains neutral with regard to jurisdictional claims in published maps and institutional affiliations.
Ready to submit your research? Choose BMC and benefit from:

- fast, convenient online submission

- thorough peer review by experienced researchers in your field

- rapid publication on acceptance

- support for research data, including large and complex data types

- gold Open Access which fosters wider collaboration and increased citations

- maximum visibility for your research: over 100M website views per year

At BMC, research is always in progress.

Learn more biomedcentral.com/submissions 